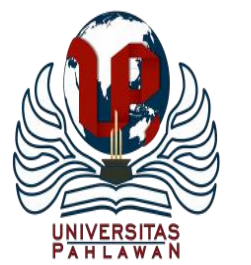

Edukatif : Jurnal Ilmu Pendidikan Volume 3 Nomor 4 Tahun 2021 Halm 1945 - 1952

EDUKATIF: JURNAL ILMU PENDIDIKAN

Research \& Learning in Education

https:/ledukatif.org/index.php/edukatif/index

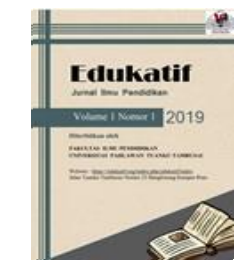

\title{
Pengaruh Latihan Lempar Tangkap Bola Menggunakan Sasaran terhadap Ketepatan Chest Pass Basket SMA
}

\author{
Muhammad Iqbal $^{1 凶}$, Syamsuramel $^{2}$, Destriani $^{3}$ \\ Pendidikan Jasmani dan Kesehatan, , Universitas Sriwijaya, Indonesia ${ }^{1,2,3}$ \\ E-mail : iqbal.muhammad23455@ gmail.com ${ }^{1}$, syamsuramel@ fkip.unsri.ac.id ${ }^{2}$, destriani@ fkip.unsri.ac.id ${ }^{3}$
}

\begin{abstract}
Abstrak
Penelitian ini bertujuan untuk mengetahui pengaruh latihan lempar tangkap bola terhadap ketepatan chest pass basket SMA Negeri 1 Indralaya Utara. Metode penelitian yang digunakan adalah metode penelitian quasy eksperiment. Data hasil posttest tes AAHPERD tertinggi yaitu 58 dan hasil tes terendah yaitu 43 dan di dapatlah mean atau rata-rata dari pretest sebesar 44,5 dan posttest sebesar 51,4 sehingga perbedaan mean pretest dan posttest sebesar 6,48. chest pass bola basket berpengaruh pada peningkatan ketepatan passing pada siswa SMA Negeri 1 Indralaya Utara sehingga latihan ini digunakan dalam latihan chest pass bola basket. Sampel penelitian yang digunakan adalah sampel yang jumlahnya sebesar populasi yaitu 30 orang. Instrumen penelitian yaitu tes chest pass bola basket. Dari hasil pengolahan dan analisis data dengan menggunakan uji normalitas data dan uji hipotesis dengan rumus uji t, bahwa latihan chest pass berpengaruh terhadap keterampilan chest pass bola basket. Hal ini dapat dilihat dari hasil analisis data melalui perhitungan rumus uji $t$ dengan kriteria $t_{\text {hitung }}$ lebih besar dari $t_{\text {tabel }}(11,36>1,70)$ dengan taraf kepercayaan $95 \%(\alpha=0,05)$ dan jumlah sampel $(\mathrm{N}=30)$, maka hipotesis yang diajukan diterima. Latihan chest pass bola basket secara signifikan memberikan pengaruh terhadap keterampilan chest pass bola basket.
\end{abstract}

Kata Kunci: Passing, Chest Pass, Bola basket.

\begin{abstract}
This study aims to determine the effect of throwing and catching the ball on the accuracy of chest pass basketball at SMA Negeri 1 Indralaya Utara. The research method used is a quasi-experimental research method. The highest AAHPERD test result data is 58 and the lowest test result is 43 and the mean or average of the pretest is 44.5 and the posttest is 51.4 so that the difference between the pretest and posttest means is 6.48. The basketball chest pass has an effect on increasing the accuracy of passing in SMA Negeri 1 Indralaya Utara students so that this exercise is used in basketball chest pass exercises. The research sample used is a sample of a population of 30 people. The research instrument is a basketball chest pass test. From the results of data processing and analysis using the data normality test and hypothesis testing with the t-test formula, that chest pass exercise affects basketball chest pass skills. This can be seen from the results of data analysis through the calculation of the t test formula with the criteria tcount greater than ttable $(11.36>1.70)$ with a 95\% confidence level $(\alpha=0.05)$ and the number of samples $(N=30)$, then the proposed hypothesis is accepted. The basketball chest pass exercise significantly influences the basketball chest pass skill.
\end{abstract}

Keywords: Passing, Chest Pass, Basketball.

Copyright (c) 2021 Muhammad Iqbal, Syamsuramel, Destriani

$\triangle$ Corresponding author

Email : iqbal.muhammad23455@gmail.com

DOI : https://doi.org/10.31004/edukatif.v3i4.971

ISSN 2656-8063 (Media Cetak)

ISSN 2656-8071 (Media Online)

Edukatif : Jurnal Ilmu Pendidikan Vol 3 No 4 Tahun 2021 p-ISSN 2656-8063 e-ISSN 2656-8071 
1945 Pengaruh Latihan Lempar Tangkap Bola Menggunakan Sasaran terhadap Ketepatan Chest Pass Basket SMA - Muhammad Iqbal, Syamsuramel, Destriani

DOI: https://doi.org/10.31004/edukatif.v3i4.971

\section{PENDAHULUAN}

Pendidikan jasmani adalah proses interaksi sistematik antara anak didik dan lingkungan yang di kelola melalui pengembangan jasmani secara efektif dan efisien menuju pembentukan manusia seutuhnya. Pembelajaran secara umum berupaya mewujudkan tujuan pembelajaran dengan baik, yaitu pembelajaran yang bermakna dan berguna dalam kehidupan siswa. Keefektifan model dan variasi metode pembelajaran yang digunakan sangat menunjang dalam keberhasilan siswa ketika dalam proses pembelajaran (Utama, 2011).

Permainan bola basket adalah salah satu olahraga yang cukup populer di masyarakat saat ini, khususnya untuk olahraga prestasi di kalangan remaja. Disamping itu olahraga basket telah mendapatkan perhatian yang cukup baik dari masyarakat dunia. Bola basket adalah salah satu cabang olahraga yang menarik dan menjadi cabang olahraga yang berkembang. Saat ini olahraga bola basket di kalangan anak muda menjadi olahraga yang bergengsi. Hal ini ditandai dengan banyaknya pertandingan yang digelar dan juga semakin bervariasinya pertandingan yang ditambahkan dengan unsur hiburan, seperti: three x three dan street ball M. Axl Rachman, M Ridwan (2019).

Permainan bola basket memiliki macam-macam passing yang sering dilakukan oleh pemain untuk menghindari penjagaan oleh lawan. Ada beberapa macam bentuk passing dalam permainan bola basket antara lain, mengoper bola dari depan dada (chest pass) dan mengoper bola memantul ke tanah/lantai (bounce pass), mengoper dari atas kepala menggunakan dua tangan (two handed), (overhead pass), mengoper dengan gaya bisbol (baseball pass), mengoper sambil berlari (shuffle pass), mengoper ke arah bawah dengan mendribel (dribble pass), mengoper dengan cara bergerak menyamping/umpan selubung (wrap around pass) dan mengoper dengan bola berada di belakang punggung (behind the back pass). Oliver dalam Hadist (2020).

Teknik dasar dalam bola basket merupakan titik awal pemain basket dalam menguasi dan meningkatkan keterampilannya dalam permainannya. Menurut PB. PERBASI (2010:18), ada 3 teknik dasar dalam bola basket yaitu operan (passing), dribbling, tembakan (shooting). Salah satu teknik yang harus di kuasai seorang pemain adalah teknik passing, karena pada era bola basket modern saat ini passing merupakan teknik yang paling berbahaya untuk mencetak angka M. Axl Rachman, M. Ridwan (2019). Salah satu metode atau cara operan yang sering dipakai untuk mempertahankan bola adalah operan dada (chest pass). Chest pass ialah memberikan bola ke teman satu tim dengan cara melakukan passing yang tepat di depan dada Yopi Meirizal, Ruslan Rusman, (2018). Chest pass merupakan operan dua tangan yang sangat penting dan sering dilakukan dalam peramainan bola basket. Operan ini juga sangat bermanfaat untuk operan jarak pendek dengan perhitungan demi kecepatan dan kecermatan karena teman yang menerima bola tidak terjaga atau terkawal oleh lawan dengan ketat (Amin, 2018). Chest pass paling sering digunakan dalam permainan bola basket. Jenis operan ini dilakukan dengan menolakkan bola dari depan dada kepada teman dengan cepat dan arah bola mendatar setinggi dada. Karena chest pass merupakan operan yang mementingkan kecepatan dan ketepatan dalam pelaksanaannya, jadi sangat berperan sekali dalam melakukan serangan cepat tanpa mudah disergap lawan (Frizki Amra, 2017).

Menurut (Muhammad \& Wismanadi, 2020) "sangat penting bagi seorang pemain untuk mengembangkan skill passing demi kesuksesan timnya". Salah satu poin yang harus ditekankan pada pemain adalah bahwa passing adalh skill yang tercepat dan terbaik untuk merubah arah serangan. Menurut Abang dalam Utama Rahmat (2021) untuk membuktikan apakah modifikasi alat latihan dapat mengoptimalkan kemampuan gerak dasar anak, maka perlu dibuktikan melalui penelitian. Dengan kata lain bahwa sarana yang dimodifikasi juga mempunyai pengaruh besar terhadap keberhasilan sebuah tujuan yang ingin dicapai. Menurut (Dinata et al., 2019) Menyatakan "Pada saat melakukan chest pass harus mampu memperkirakan arah gerakan pemain satu tim sehingga saat rekan setim menerima bola, dapat langsung melakukan posisi triple threat dengan menggunakan modifikasi alat bisa menjadikan target sebagai pengganti sasaran. Hal ini bertujuan agar tidak terjadi turn over atau kesalahan dalam menerima passing yang tidak mengenai target atau 
1946 Pengaruh Latihan Lempar Tangkap Bola Menggunakan Sasaran terhadap Ketepatan Chest Pass Basket SMA - Muhammad Iqbal, Syamsuramel, Destriani

DOI: https://doi.org/10.31004/edukatif.v3i4.971

pemain yang diinginkan. Dengan demikian prinsip dasar chest pass merupakan berbagai hal yang perlu diperhatikan pada saat melakukan chest pass merupakan berbagai hal yang peru diperhatikan pada saat melakukan chest pass agai chest pass menjadi lebih efektif dan efisien.

Operan setinggi dada (chest pass) merupakan operan yang sering digunakan dalam permainan bola basket yang dilakukan untuk memindahkan bola dari seorang pemain kepada pemain lainnya, namun sering kali berbagai macam ajang pertandingan bola basket yang diikuti, pemain tidak dapat melakukan chest pass dangan baik sehingga merugikan regu sendiri. Adapun yang menjadi persoalan kesalahan yang dilakukan oleh pemain adalah bola yang dioper sering melenceng atau tidak sampai ke tangan penerima sehingga chest pass yang dilakukan tidak tepat pada sasaran yang diinginkan (Ilham ,2011). Chest pass bisa jadi tidak efektif apabila dalam pelaksanaannya tidak dilakukan dengan baik. Seperti saat melakukan chest pass bola dapat di rampas jika tidak dilakukan dengan hati-hati sehingga bola dikuasaai pihak lawan. Maka dari itu diperlukan latihan yang intensif untuk dapat melakukan chest pass dengan baik yaitu dengan kemampuan chest pass, akurasi ketepatan dan kekuatan otot tangan dalam melakukan operan (Boy dalam Hadist ,2020).

Mengoper atau melempar bola terdiri atas tiga cara yaitu, melempar bola dari depan dada (chest pass) yang dilakukan dari dada ke dada teman dengan cepat dalam permainan, melempar bola memantul ke tanah atau lantai (bounce pass), dan melempar bola dari atas kepala (over head pass) (Indarto, 2013).

Manfaat penelitian ini secara teoritis bermanfaat dalam memberikan suatu informasi pada ilmu pengetahuan, terutama dibidang Ilmu Keolahragaan yang dikaitkan dengan pengaruh latihan lempar tangkap menggunakan sasaran terhadap ketepatan chest pass bola basket SMA Negeri 1 Indralaya Utara. Sedangkan hasil penelitian ini diharapkan dijadikan acuan yang bermanfaat bagi peneliti atau Pembina olahraga basket dalam mengembangkan modifikasi alat untuk latihan, sehingga memberikan motivasi latihan khususnya materi passing. Latihan adalah suatu proses yang dilakukan berulang-ulang dalam jangka waktu yang relatif lama, dengan beban latihan yang semakin bertambah, agai terjadi peningkatan terhadap rangsangan gerak secara menyeluruh terhadap tubuh. (Rahardian dalam Shabih , 2021).

Menurut (Hal Wissel dalam Sriwahyuni, 2014) menyatakan "Gunakan tipuan berpura-pura sebelun anda lewat. Gunakan penglihatan peripheral anda untuk melihat target tanpa melihat penerima anda. Gunakan elemen kejutan". Sedangkan menurut (Muhammad Ali: 2018). Salah satu tindakan yang dapat dilakukan untuk meningkatkan hasil chest pass yaitu melalui modifikasi media yang dapat membantu siswa dalam melakukan latihan pemainan bola basket. Pelaksanaan penggunaan modifikasi media dapat diterapkan dengan mengembangkan gerak dasar chest pass pada siswa dengan menggunakan modifikasi media ban bekas melalui pendekatan bermain bola basket.

Menurut Rahmat Pamuji, (2013) bola basket sangat cocok untuk ditonton karena biasa dimainkan di dalam ruangan maupun luar ruangan olahraga tertutup dan hanya memerlukan lapangan yang relative kecil. Selain itu, permainan bola basket juga lebih kompetitif karena tempo permainan cenderung lebih cepat jika dibandingkan dengan olahraga bola yang lain, seperti voli dan sepak bola. Ada 3 teknik dasar bola basket : passing, dribbling, shooting. Bola basket merupakan olahraga berselang yang menggabungkan perubahan cepat dan berulang-ulang dalam arah gerakan (Iqroni, 2017).

Menurut Windo Wiria Dinata, Lismadiana (2019) menyatakan "Pada saat melakukan passing harus mampu memperkitakan arah gerakan pemain satu tim sehingga saat rekan setim menerima bola, dapat langsung melakukan posisi triple threat dengan menggunakan modifikasi alat bisa menjadikan target sebagai pengganti sasaran. Hal ini bertujuan agar tidak terjadi turnover atau kesalahan dalam melakukan passing yang tidak mengenai target atau pemain yang diinginkan. Dengan demikian prinsip dasar passing merupakan berbagai hal yang perlu diperhatikan pada saat melakukan passing agar passing menjadi lebih efektif dan efisien. Dalam Tri Ani Hastuti dalam Rama, (2018) yang menyatakan bahwa ekstrakurikuler adalah kegiatandi luar jam pelajaran biasa dan pada waktu libur sekolah yang dilakukan baik di sekolah maupun di luar sekolah, dengan tujuan untuk memperdalampengetahuan siswa, mengenal hubungan antara berbagai pelajaran, 
1947 Pengaruh Latihan Lempar Tangkap Bola Menggunakan Sasaran terhadap Ketepatan Chest Pass Basket SMA - Muhammad Iqbal, Syamsuramel, Destriani

DOI: https://doi.org/10.31004/edukatif.v3i4.971

menyalurkan bakat dan minat, serta melengkapi upaya pembinaan manusia seutuhnya. Dapat disimpulkan bahwa kegiatan ekstrakurikuler adalah kegiatan yang dilakukan di luar jam pelajaran sekolah yang bertujuan untuk mengembangkan dan meningkatkan bakat siswa dalam bidang tertentu. Selain itu juga akan membantu siswa untuk lebih memahami mengenai suatu hal yang tidak dapat dimengerti pada saat jam sekolah.

Menurut Wiguna \& Subari, 2017) latihan merupakan aktivitas jasmani atau olahraga yang telah ditentukan tujuannya, dirancang secara detail dan bertahap untuk penyesuaian perkembangan fisiologi dan psikologi. Maksudnya, dalam suatu latihan yang dilakukan akan memberikan manfaat bagi yang melakukannya baik pengoptimalan prestasi dan penampilan olahraga.

\section{METODE PENELITIAN}

Rancangan penelitian ini menggunakan rancangan One Group Pretest- Posttest Design. Sebelum diberi perlakuan, terlebih dahulu diberikan tes awal (pretest) chest pass dengan menggunakan AAHPERD (American Alliance for Health, Physical Education, Recreation and Dance) Basketball Test setelah itu baru diberi perlakuan selama enam minggu kemudian diberikan tes akhir (post test). Rancangannya dapat dilihat sebagai berikut :
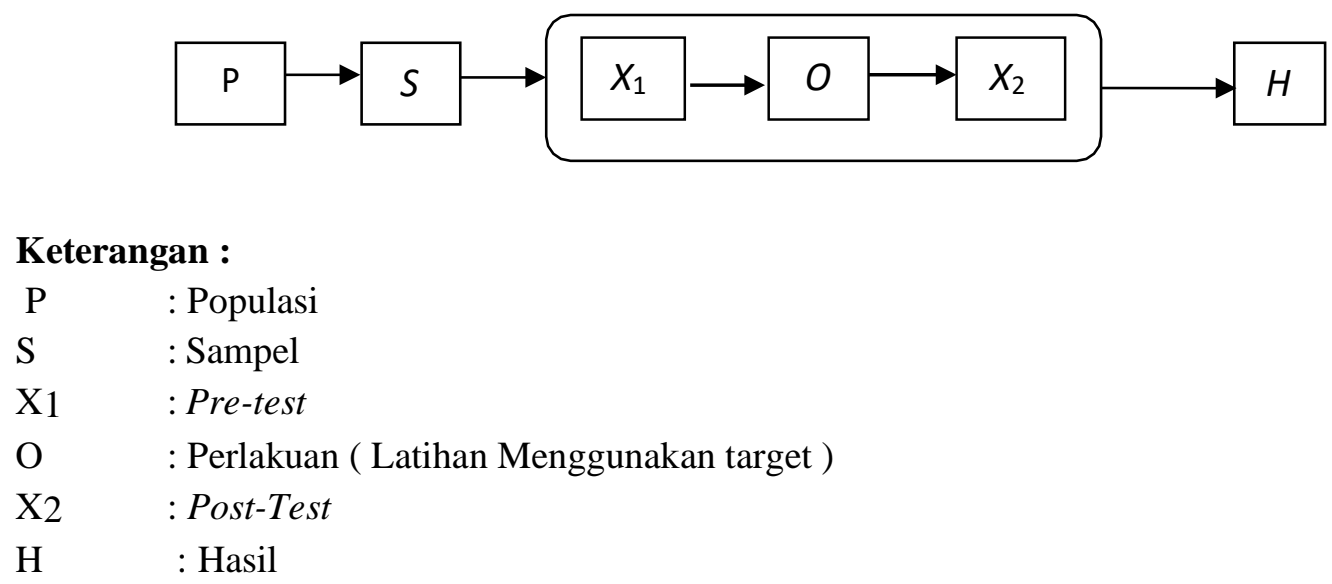

Instrumen Penelitian

Penelitian sampel berjumlah 30 orang siswa ekstrakurikuler bola basket sebagai kelompok eksperimen. Teknik sampel dalam penelitian ini adalah total sampling, yaitu; siswa yang mengikuti kegiatan ekstrakulikuler bola basket SMA Negeri 1 Indralaya Utara yang berjumlah 30 orang.

Teknik pengumpulan data penelitian dilakukan tes dan pengukuran. Proses penelitian diawali dengan memberikan pemanasan kepada peserta dan memberikan petunjuk tentang pelaksanaan tes. Pengambilan data dilakukan satu hari pretest dan posttest. Pada setiap tes diawasi oleh dua tester, dua tester mempunyai tugas masing-masing, yaitu sebagai pemberi aba-aba atau pengawas dan penghitung hasil. Tes seberapa pengaruh latihan passing menggunakan ban target terhadap ketepatan chest pass, perlu diketahui dan harus dilakukan atlet pada saat melakukan tes awal (pretest) maupun test akhir (posttest) chest pass dilakukan berdasarkan ketentuan sebagai berikut :

1) Testi berdiri di belakang garis 8 kaki dengan membawa bola dan menghadap ke target $\mathrm{A}$ di dinding.

2) Pada aba-aba "yak"/"go"/bunyi peluit, testi melakukan operan dada (chest pass) ke target A, kemudian menerima bola pantulan sambil bergeser ke target B dan melakukan operan dada (chestpass).

3) Testi melakukan operan dada sampai pada target $F$ kemudian pada target $F$ melakukan operan dada sebanyak dua kali lalu bergeser kembali ke E,D,C dan seterusnya.

4) Testi diberikan tiga kali kesempatan dan masing-masing kesempatan berdurasi 30 detik. Kesempatan 
1948 Pengaruh Latihan Lempar Tangkap Bola Menggunakan Sasaran terhadap Ketepatan Chest Pass Basket SMA - Muhammad Iqbal, Syamsuramel, Destriani

DOI: https://doi.org/10.31004/edukatif.v3i4.971

pertama merupkan latihan.

5) Hanya operan dada yang diperbolehkan.

6) Skor 2 apabila operan dada mengenai tepat di dalam kotak sasaran atau garis sasaran.

7) Skor 1 apabila operan dada mengenai ruang antara dua kotak sasaran.

8) Skor 0 apabila kaki testi melewati garis batas operan; operan mengenai dua kali pada kotak B, C, D atau E; melakukan operan selain menggunakan operan dada.

9) Skor tes ini dijumlahkan dari dua kali kesempatan pelaksanaan, yakni pelaksanan kedua dan ketiga.

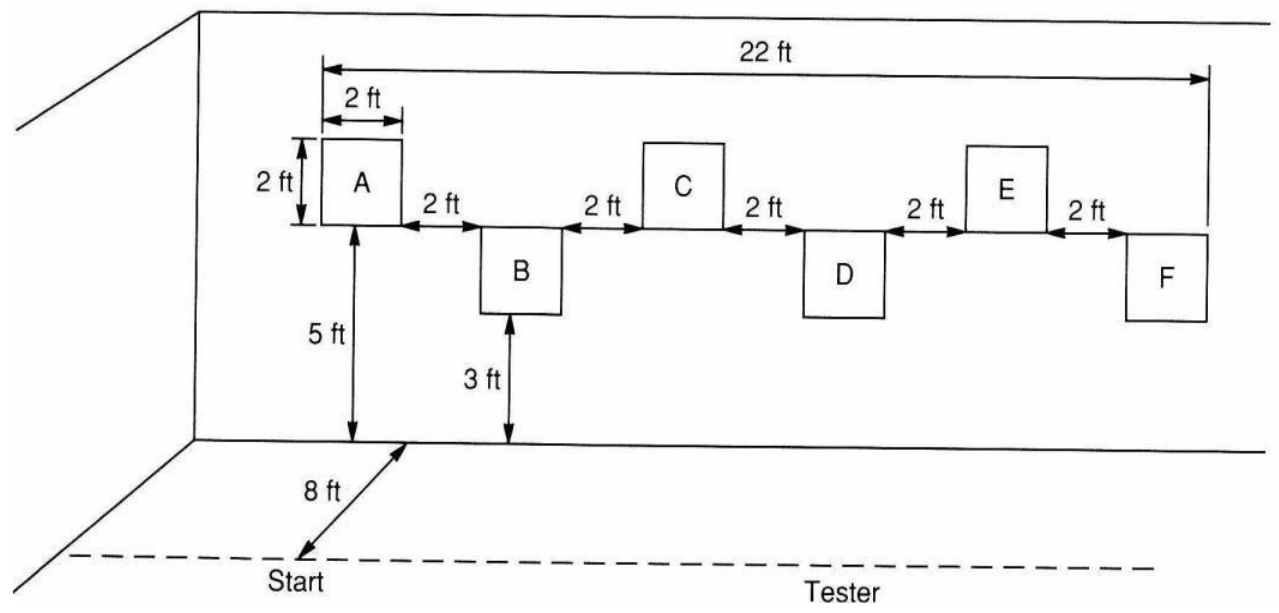

Gambar 1 Tes AAHPERD

Sumber : Bradford N. Strand\& Rolayne Wilson dalam Hadist, (2020)

Berikut untuk menganalisis data tersebut pada penelitian ini yaitu:

1. Mengumpulkan hasil kasar atau raw score dari setiap item test, yaitu passing test,yang telah dilaksanakan sebanyak 3 kali pada masing-masing tes sesuai petunjuk pelaksanaan AAHPERD Basketball Test

2. Setelah itu diubah menjadi skor $t$ agar memiliki satuan yang sama

3. Hasil skor t kemudian dicari nilai maksimum, minimum, rerata (Mean), standar deviasi (SD), median, modus dan jumlah

4. Keempat macam skor t selanjutnya dimasukkan ke dalam 5 kategori yaitu Baik Sekali, Baik, Cukup, Kurang dan Kurang Sekali

5. Untuk menentukan kategori tersebut menggunakan rumus statistik.

Menurut David K Miller (2012: 88) pengkategorian berdasarkan Mean dan Standar Deviasi sebagai berikut:

\begin{tabular}{|r|c|l|}
\hline \multicolumn{1}{|c|}{ No } & \multicolumn{1}{|c|}{ Rumus } & \multicolumn{1}{|c|}{ Kategori } \\
\hline 1 & $(\mathrm{M}+1,5 \mathrm{SD}) \leq \mathrm{X}$ & BaikSekali \\
\hline 2 & $(\mathrm{M}+0,5 \mathrm{SD}) \leq \mathrm{X}<(\mathrm{M}+1,5 \mathrm{SD})$ & Baik \\
\hline 3 & $(\mathrm{M}-0.5 \mathrm{SD}) \leq \mathrm{X}<(\mathrm{M}+0,5 \mathrm{SD})$ & Cukup \\
\hline 4 & $(\mathrm{M}-1,5 \mathrm{SD}) \leq \mathrm{X}<(\mathrm{M}-0,5 \mathrm{SD})$ & Kurang \\
\hline 5 & $\mathrm{X}<(\mathrm{M}-1,5 \mathrm{SD})$ & KurangSekali \\
\hline
\end{tabular}

Mencari simpangan baku.

$$
S^{2}=\frac{n \sum f_{1} X_{1}^{2}-\left(\sum f_{1} X_{1}\right)^{2}}{n(n-1)}(\text { sudjana, } 2005: 95)
$$


1949 Pengaruh Latihan Lempar Tangkap Bola Menggunakan Sasaran terhadap Ketepatan Chest Pass Basket SMA - Muhammad Iqbal, Syamsuramel, Destriani

DOI: https://doi.org/10.31004/edukatif.v3i4.971

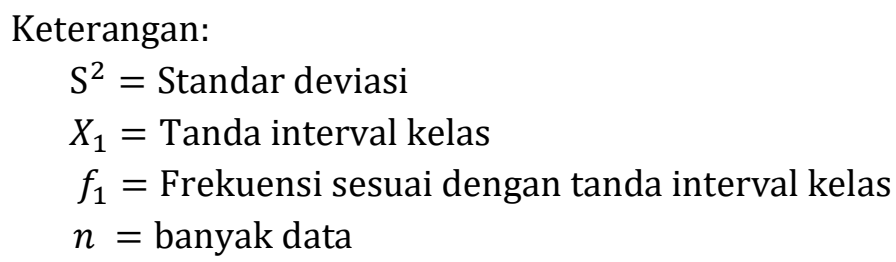

Memasukan nilai hitung yang didapat (modus, rata-rata, dan standar deviasi) kedalam rumus koefesien pekoefesien person.

\section{HASIL DAN PEMBAHASAN PENELITIAN}

Deskripsi data hasil pretest pada siswa yang mengikuti ekstrakurikuler basket SMA Negeri 1 Indralaya Utara dan setelah diberikan perlakuan berupa latihan chest pass menggunakan modifikasi alat selama 6 minggu dengan frekuensi latihan 3 kali seminggu setelah itu dilakukan tes akhir atau posttest untuk melihat ada atau tidaknya perubahan setelah diberikan perlakuan, berikut ini adalah hasil pretest. Hasil pretest yang telah dilakukan pada tanggal $25 \mathrm{Mei}-3$ Juli 2021 diperoleh hasil :

1. Hasil tes AAHPERD tertinggi adalah 56.

2. Rentangnya adalah 21 .

3. Rata-rata tes AAHPERD kelompok eksperimen sebesar 46,23

Tabel 1 Distribusi Data Instrumen Tes AAHPERD (Pretest)

\begin{tabular}{lcccccc}
\hline Variabel & $\mathrm{N}$ & $\begin{array}{c}\text { Jumlah } \\
\text { Tertinggi }\end{array}$ & $\begin{array}{c}\text { Jumlah } \\
\text { Terendah }\end{array}$ & Rentangan & Mean & SB \\
\hline Tes & 30 & 54 & 34 & 20 & 44,5 & 5,82 \\
AAHPERD & & & & & & \\
\hline
\end{tabular}

Berdasarkan tabel 4.1 dapat diketahui jumlah nilai tertinggi 54, jumlah nilai terendah 34, rentangannya sebesar 20, rata-rata yang didapat dari pretest yaitu 44,5 serta simpangan baku yang di dapatkan dari hasil pretest yaitu 5,82.

Berdasarkan data hasil latihan selama enam minggu, terdapat peningkatan hasil chest pass pada kelompok eksperimen, di bawah ini adalah hasil posttest kelompok eksperimen dalam bentuk data frekuensi dan histogram. Hasil posttest yang telah dilakukan pada tanggal 3 Juli 2021 untuk kelompok eksperimen diperoleh hasil :

Tabel 2 Distribusi Data Instrumen Tes AAHPERD (Posttest)

\begin{tabular}{ccccccc}
\hline Variabel & $\mathrm{N}$ & $\begin{array}{c}\text { Jumlah } \\
\text { Tertinggi }\end{array}$ & $\begin{array}{c}\text { Jumlah } \\
\text { Terendah }\end{array}$ & Rentangan & Mean & SB \\
\hline AAHPERD & 30 & 58 & 43 & 15 & 51,4 & 0,81 \\
\hline
\end{tabular}

Berdasarkan tabel 4.3 dapat diketahui jumlah nilai tertinggi 58, jumlah nilai terendah 43 , rentangannya sebesar 15, rata-rata yang didapat dari posttest yaitu 51,15 serta simpangan baku yang di dapatkan dari hasil posttest yaitu 0,81

Tabel 3 Daftar Perbandingan Hasil Pretest dan Posttest Tes AAHPERD

\begin{tabular}{cccccc}
\hline Hasil & $\mathrm{N}$ & Teringgi & Terendah & Mean & Perbedaan Mean \\
Pretest dan Posttest
\end{tabular}


1950 Pengaruh Latihan Lempar Tangkap Bola Menggunakan Sasaran terhadap Ketepatan Chest Pass Basket SMA - Muhammad Iqbal, Syamsuramel, Destriani

DOI: https://doi.org/10.31004/edukatif.v3i4.971

\begin{tabular}{cccccc}
\hline Pretest & 30 & 54 & 34 & 44,5 & 6,48 \\
\hline Posttest & 30 & 58 & 43 & 51,4 & \\
\hline
\end{tabular}

Perbandingan hasil pretest dan posttest di atas dapat dilihat hasil perbandingannya dari pretest tes AAHPERD tertinggi yaitu 54 dan terendah34. Data hasil posttest tes AAHPERD tertinggi yaitu 58 dan hasil tes terendah yaitu 43 dan di dapatlah mean atau rata-rata dari pretest sebesar 44,5 dan posttest sebesar 51,4 sehingga perbedaan mean pretest dan posttest sebesar 6,48

Berdasarkan hasil perhitungan statistic "uji t" didapat hasil 11,36 sedangkan $\mathrm{T}_{\text {tabel }}$ adalah 1,70 yang diperoleh dari tabel distribusi $\mathrm{T}$ dengan $\mathrm{dk}(30-1)=29$ dan taraf kepercayaan 95\% $(\alpha=0,05)$, tercantum dalam tabel. Kriteria pengujian hipotesis terima $\mathrm{H}_{1}$ jika $\mathrm{T}_{\text {hitung }}>\mathrm{T}_{\text {tabel }}(1-\alpha)$, karena $\mathrm{T}_{\text {hitung }}(11,36)>\mathrm{T}_{\text {tabel }}(1,70)$ maka terdapat perbedaan yang signifikan antara pre-test dan post-test, dengan demikian maka hipotesis $\mathrm{H}_{\mathrm{o}}$ ditolak dan hipotesis $\mathrm{H}_{1}$ diterima. Pernyataan $\mathrm{H}_{1}$ yaitu : ada pengaruh latihan lempar tangkap bola menggunakan sasaran terhadap ketepatan chest pass basket SMA Negeri 1 Indralaya Utara". Tujuan latihan secara umum adalah membantu para pembina, pelatih, guru olahraga agar dapat menerapkan dan memiliki konseptual serta keterampilan dalam membantu mengungkapkan potenti atlet mencapai puncak prestasi. Sedangkan sasaran latihan secara khusus adalah untuk meningkatkan kemampuan dan kesiapan atlet dalam mencapai puincak prestasi.

Berdasarkan hasil penelitian di atas dapat ditunjukkan bahwa latihan menggunakan sasaran dapat digunakan untuk meningkatkan hasil ketepatan chest pass bola basket putra SMA Negeri 1 Indralaya Utara. Hal ini dapat dilihat dari adanya pengingkatan pretest dan posttest setelah diberi perlakuan latihan selama 6 minggu dengan frekuensi 3 kali dalam seminggu menggunakan sasaran. Hal ini sejalan dengan pendapat (syamsuramel, 2012) bahwa latihan merupakan suatu proses yang sistematis dalam mempersiapkan atlet pada tingkat tertinggi penampilannya yang dilakukan secara berulang-ulang dengan beban yang semakin meningkat. Penelitian ini bertujuan untuk meningkatkan hasil chest pass menggunakan latihan lempar tangkap bola, pengambilan data telah dilaksanakan pada 30 siswa putra SMA Negeri 1 Indralaya Utara.

Prestasi dapat diraih dengan pembinaan yang berjenjang dan dengan latihan-latihan khusus. Evaluasi dapat dilakukan dengan cara mengukur kemampuan teknik-teknik dasar permainan bola basket. Karena dengan teknik yang baik dan benar akan dapat meningkatkan prestasi pemain bola basket. Terdapat banyak perkembangan dalam upaya untuk meningkatkan kemampuan peserta didik atau peserta latihan khususnya dalam permainan bola basket ini, seperti pada pengembangan sarana, prasarana, dan peraturan dalam permainan bola basket. (Destriani et al., 2019).

Menurut Lutan dalam Husdarta (2011:179) tujuan memodifikasi dalam pendidikan jasmani yaitu agar: 1) siswa memperoleh kepuasan dalam mengikuti pelajaran, 2) meningkatkan kemungkinan keberhasilan dalam berprestasi, dan 3) siswa dapat melakukan pola gerak secara benar.

Penelitian ini bertujuan untuk meningkatkan hasil ketepatan passing menggunakan latihan AAHPERD, pengambilan data dilaksanakan pada 30 orang siswa putra SMA Negeri 1 Indralaya Utara. Penelitian ini termasuk populasi, dikarenakan peneliti mengambil seluruh populasi untuk dijadikan sampel berjumlah 30 orang siswa putra sebagai kelompok eksperimen. Kelompok ini diberikan perlakuan berupa latihan AAHPERD selama 6 minggu dengan frekuensi 3 kali seminggu, setelah 6 minggu latihan, kelompok penelitian dilakukan tes akhir atau posttest. Dari nilai kemiringan kurva untuk data pretest kelompok eksperimen adalah 0,14 dan kemiringan kurva data posttest kelompok eksperimen 0,81. Berdasarkan nilainilai tersebut, maka pada saat pretest maupun posttest data berdistribusi normal, yaitu terletak antara (-1) dan $(+1)$. 
1951 Pengaruh Latihan Lempar Tangkap Bola Menggunakan Sasaran terhadap Ketepatan Chest Pass Basket SMA - Muhammad Iqbal, Syamsuramel, Destriani

DOI: https://doi.org/10.31004/edukatif.v3i4.971

\section{KESIMPULAN}

Berdasarkan hasil dari perhitungan statistik ini dapat ditarik kesimpulan bahwa latihan passing dengan modifikasi alat terhadap ketepatan chest pass bola basket berpengaruh pada peningkatan ketepatan passing pada siswa SMA Negeri 1 Indralaya Utara sehingga Latihan ini digunakan dalam Latihan chest pass bola basket.

\section{DAFTAR PUSTAKA}

Ajiansyah, A., Haetami, M., \& Triansyah, A., "Pengaruh Media Bantu Ban Terhadap Hasil Shooting Futsal Pada Peserta Didik Mts Negeri 1 Pontianak. Jurnal Pendidikan dan Pembelajaran ,7(9).

Amin, B. F. (2018). Pembelajaran Operan Dada (Chest Pass) Dalam Permainan Basket Melalui Metode Mengajar Penemuan Terpimpin Pada Siswa Kelas viii SMP Negeri 1 Jonggol. Jurnal Ilmiah Sport Coaching and Education, 2(1), 61-66.

Dinata et.al. (2019). Pengaruh Latihan Medichine Ball dan Koordinasi Terhadap Kemampuan Passing Peserta Ekstrakurikuler Bola Basket. Jurnal Sporta Santika, 4(1), 21-40.

Frizki Amra, (2017) Koordinasi Mata Tangan Terhadap Kemampuan Chest Pass Bola Basket SMA Pembangunan Laboratorium Padang. Jurnal Menssana 2(2) 36-48

Hadist, M. (2020). Pengaruh Latihan Passing Dengan Modifikasi Alat Terhadap Ketepatan Chest Pass Siswa Ekstrakurikuler Bola Basket SMA Negeri 1 Indralaya Utara. Skripsi. Indralaya: Universitas Sriwijaya.

Ilham, (2011). Hubungan Kekuatan Otot Lengan Dengan Kemampuan Chest Pass Pemain Bola Basket Siswa SMP N 11 Kota Jambi. Jurnal Penelitian Universitas Jambi Seri Himaniora, 13(1), 13-18.

Iqroni, D. (2017). Model tes keterampilan dasar dan kondisi fisik untuk mengidentifikasi bakat calon atlet bolabasket. Jurnal Keolahragaan, 5(2), 142. https://doi.org/10.21831/jk.v5i2.15595

Indarto, J. (2013). perpustakaan.uns.ac.id digilib.uns.ac.id.

Muhammad, S. I. R., \& Wismanadi, H. (2020). Analisis Shooting Free Throw Ricky Rubio MVP (Most Valuable Player) FIBA World Cup 2019. Jurnal Kesehatan Olahraga, 8(4), 211-216.

Muhammad Ihsan Shabih, Iyakrus, \& Destriani. (2021). Latihan Zig-Zag Terhadap Kelincahan Menggiring Bola Pada Atlet Sepak Bola. Jurnal Kejaora (Kesehatan Jasmani Dan Olah Raga), 6(1), 145-152. https://doi.org/10.36526/kejaora.v6i1.1289

PB. PERBASI. (2010). Official Basketball Rules. Jakarta: Bidang III PERBASI. Perbasi. 2006. Bola Basket untuk semua. Jakarta: PB Perbasi PB Perbasi. 2010. Terjemahan Peraturan Permainan Bola Basket. Jakarta:

Rahman, M. A., \& Ridwan, M. (2019). Pengaruh Latihan Operan Menyilang Terhadap Ketepatan Chest Pass Bola Basket. Jurnal Patriot, 1(03), 334-340

Rahmat Pamuji, (2013) Pengaruh Gaya Mengajar Komando dan Gaya Mengajar Resiprokal Terhadap Hasil Belajar Chest Pass Dalam Permainan Bola Basket. Jurnal Pedagogik. 1(1) 24-33

Sriwahyuni Adga. (2014) Pengaruh Permainan Kecil Terhadap Hasil Belajar Gerak Dasar Dribble Bola Basket. Jurnal Pendidikan Olahraga dan Kesehatan. 2(2), 423-427

Tri Ani Hastuti \& Rama (2018) Pengaruh Latihan Beban Menggunakan Katrol Terhadap Hasil Servis Atas Pada Siswa Ekstrakurikuler Bola Voli SMAN 1 Indralaya.

Utama, A. M. B. (2011). Pembentukan Karakter Anak Melalui Aktivitas Bermain Dalam Pendidikan Jasmani. Jurnal Pendidikan Jasmani Indonesia, 8(1), 1-9.

https://journal.uny.ac.id/index.php/jpji/article/view/3477

Utama, R. V, dkk. (2021). Pengaruh Latihan Passing Menggunakan Media Ban Bekas Terhadap Ketepatan 
1952 Pengaruh Latihan Lempar Tangkap Bola Menggunakan Sasaran terhadap Ketepatan Chest Pass Basket SMA - Muhammad Iqbal, Syamsuramel, Destriani

DOI: https://doi.org/10.31004/edukatif.v3i4.971

Chest Pass Pada Team Pra PORPROV Kabupaten Kepahiang. Jurnal Ilmiah Pendidikan Jasmani, 2(1),102-113.

Wiguna \& Subari (2017) Rancang Bangun Sistem Monitoring Ketinggian Air dan Kelembaban Tanah Pada Penyiram Tanaman Otomatis Dengan HMI (Human Machine Interface) Berbaris Raspberry PI Menggunakan Software Node-Red. Jurnal Gema Teknologi, 19(3) 1-6

Windo Wiria Dinata, Lismadiana (2019) Pengaruh Latihan Medicine Ball dan Koordinasi Terhadap Kemampuan Passing Peserta Ekstrakurikuler Bola Basket. Jurnal Sporta Saintika, 4(1) 21-40

Yopi Meirizal, Ruslan Rusman, (2018) Hubungan Komunikasi Interpersonal Pelatih Terhadap Motivasi Berprestasi Atlet Unit Kegiatan Mahasiswa. Jurnal Kependidikan Jasmani dan Olahraga. 2(1) 5-9 